\title{
Histopathology of intersymphyseal band and its correlation with continence in bladder exstrophy repair
}

\author{
Bharati K. Kulkarni, Nandita Saxena* (D), Shyam S. Borwankar, Hemant N. Lahoti, Pooja Multani and Dipesh Goel
}

\begin{abstract}
Background: Urinary incontinence is a major problem in operated exstrophy patients. Most of the repairs described in literature stress on the importance of dividing the intersymphyseal band (ISB) to place the bladder in the pelvis. But the origin of this band and its importance has hardly been discussed in literature. The purpose of this study is to establish the nature of tissue the ISB is composed of. This can be used to determine its role in the surgical management of exstrophy epispadias complex (EEC) patients.

Results: Thirty out of 33 operated patients demonstrated smooth muscle with/without fibrous tissue in the sections taken through the ISB.

A significant percentage of patients $\left(x^{2}=38.319, p<0.0001\right)$ in whom this band was reconstructed around the bladder neck gradually became continent/partly continent with an increase in the dry interval with time.

Conclusion: It can be a considerable factor to pay attention to the step of wrapping the ISB around the bladder neck during EEC repair. This serves to function as the smooth muscle of the bladder neck as proven histologically in our operated patients. It may have a role to support future continence in these patients.
\end{abstract}

Keywords: Exstrophy bladder, Intersymphyseal band, Smooth muscle, Continence

\section{Background}

The importance of the intersymphyseal band (ISB) in the repair of exstrophy-epispadias complex (EEC) is highlighted in the need to divide this band in order to push the bladder into the pelvis [1]. The origin of this structure considering its normal anatomic counterpart largely remains vague. Our study attempts to define the origin of this structure by using histopathology to establish that this structure actually represents the smooth muscle of the bladder neck.

The role of the bladder neck musculature in normal urinary continence is well known. Dynamic resistance offered at the level of the bladder outlet requires smooth coordination between the bladder neck and the detrusor muscle to keep an individual dry until he/she volitionally

* Correspondence: drnanditasaxena@gmail.com

Deparment of Pediatric Surgery, Dr. D. Y. Patil Hospital, Navi Mumbai, Maharashtra 400706, India

\section{Springer Open}

voids [2]. To achieve this normal physiology, normal anatomy must be restored.

Instead of merely dividing the ISB during primary exstrophy repair, reconstruction of this band by wrapping it around the bladder neck restores normal anatomy in EEC patients. This reconstructed ISB may play a significant role in keeping patients dry post-operatively. This is because it now helps to develop a near normal mechanism of providing a dynamic resistance to urine flow at the bladder neck or outlet.

Our study thus hypothesizes that the ISB represents nothing but the smooth muscle of the bladder neck and plays a significant role in making operated EEC patients' continent.

\section{Methods}

Data from the 33 patients of EEC who had undergone anatomical repair of EEC was collected after screening (c) The Author(s). 2021 Open Access This article is licensed under a Creative Commons Attribution 4.0 International License, which permits use, sharing, adaptation, distribution and reproduction in any medium or format, as long as you give appropriate credit to the original author(s) and the source, provide a link to the Creative Commons licence, and indicate if changes were made. The images or other third party material in this article are included in the article's Creative Commons licence, unless indicated otherwise in a credit line to the material. If material is not included in the article's Creative Commons licence and your intended use is not permitted by statutory regulation or exceeds the permitted use, you will need to obtain permission directly from the copyright holder. To view a copy of this licence, visit http://creativecommons.org/licenses/by/4.0/. 
for inclusion and exclusion criteria from 2003 to date. These comprised of 16 males (48.5\%) and 17 females (51.5\%).

The average age at which surgery was done was 1.78 years (range 8 months to 6 years) with a median of 0.67 years (8 months). Primary repair was deferred till 8 months of age due to higher incidence of post-operative sepsis in younger neonates and infants.

The patients were divided into 2 groups:

1. Primary repair cases: 26 in number $(78.8 \%)$ and

2. Redo cases: 7 in number (21.2\%) who had developed wound dehiscence after primary repair.

\section{Inclusion criteria}

1. All cases of primary and failed exstrophy repair.

2. Only those cases in whom intraoperative biopsy of the ISB was taken and sent for histopathology

3. Follow-up data was available

\section{Exclusion criteria}

1. For the histopathological analysis, no patients were excluded.

2. For the assessment of continence, recently operated patients ( $<6$ months), patients undergoing augmentation cystoplasty and those lost to followup were excluded.

\section{Study center}

The data from patients was collected from various centres to which the author is affiliated.

\section{Study procedure}

The data related to following parameters was collected and entered in the excel sheet for each of the primary and redo cases of EEC:

1. Biopsy report of ISB: the histopathological staining method used was the hematoxylin and eosin stain to demonstrate the tissue forming the ISB. Two types of tissue were found to be present:

a. Smooth muscle bundles appeared as sheets of spindle shaped cells with a central nucleus without striations.

b. Collagenous tissue arranged haphazardly suggestive of fibrosis.

2. Achievement of continence: Continence was defined as the ability to hold urine and void volitionally without leaking urine in between voids. The criteria used to measure this were the longterm measure of the dry interval of successfully operated exstrophy patients by anatomical repair procedure.

3. Continence was correlated with the nature of tissue in the ISB using statistical analysis-chi-square test.

\section{Operative procedure}

In all patients, the surgery carried out was the anatomical repair of exstrophy as mentioned in a previous article by the same author [2]. During surgery, the ISBs were clearly defined on either side of the bladder plate and cut from their attachment to the superior pubic rami (Fig. 1). These bands are whitish in color in contrast to red striated musculature of pelvic floor. Their attachment to bladder was left as such. Biopsies were taken from the ISB at the site of attachment to pubic bones on either side. The bands were then approximated in the midline over a closed bladder at the level of its outlet (Fig. 2).

Post-operatively, all patients were started on chemoprophylaxis and oxybutynin.

Assessment of continence was started 6 months postoperatively and then yearly. Bladder growth and capacity as well as status of the upper tracts was also assessed using ultrasound examination (US), sometimes along with micturating cystourethrogram (MCU) in the same follow-up.

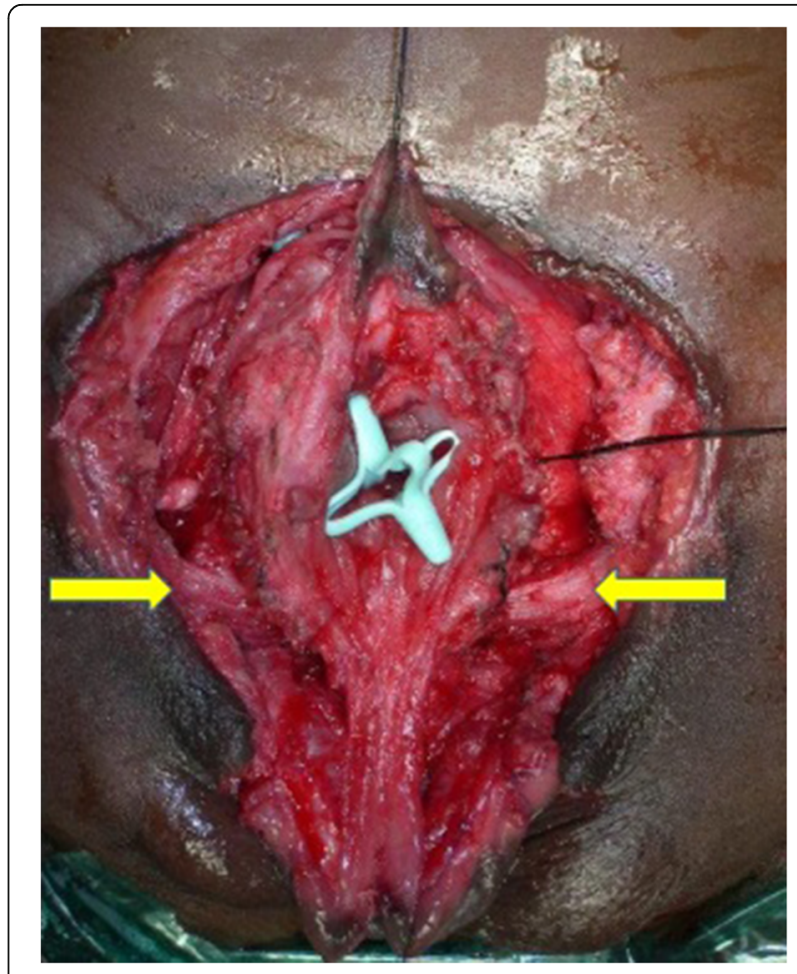

Fig. 1 Intraoperative photograph showing the dissected Intersymphyseal bands (yellow arrows) 
A.

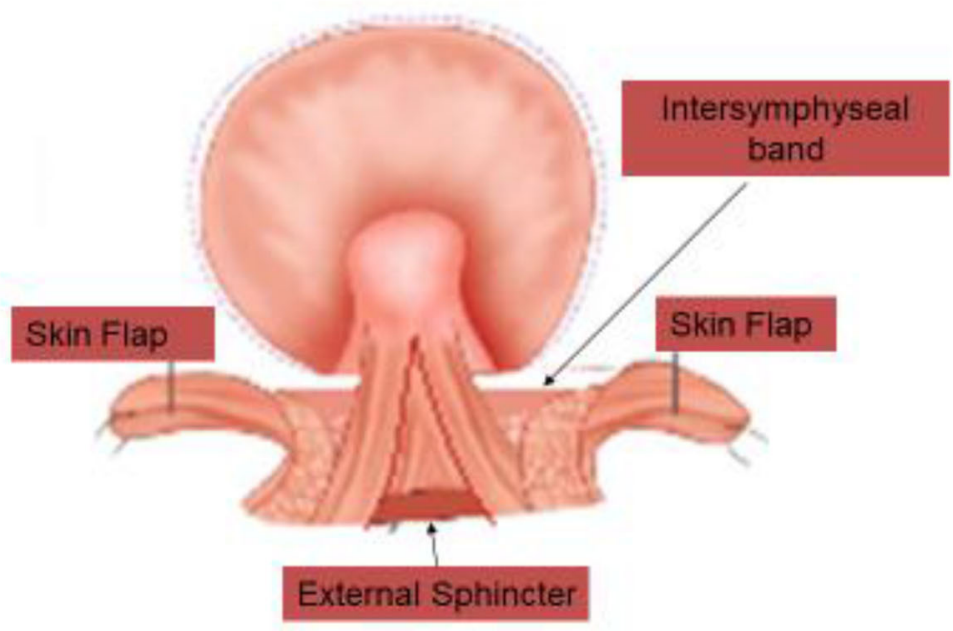

B.

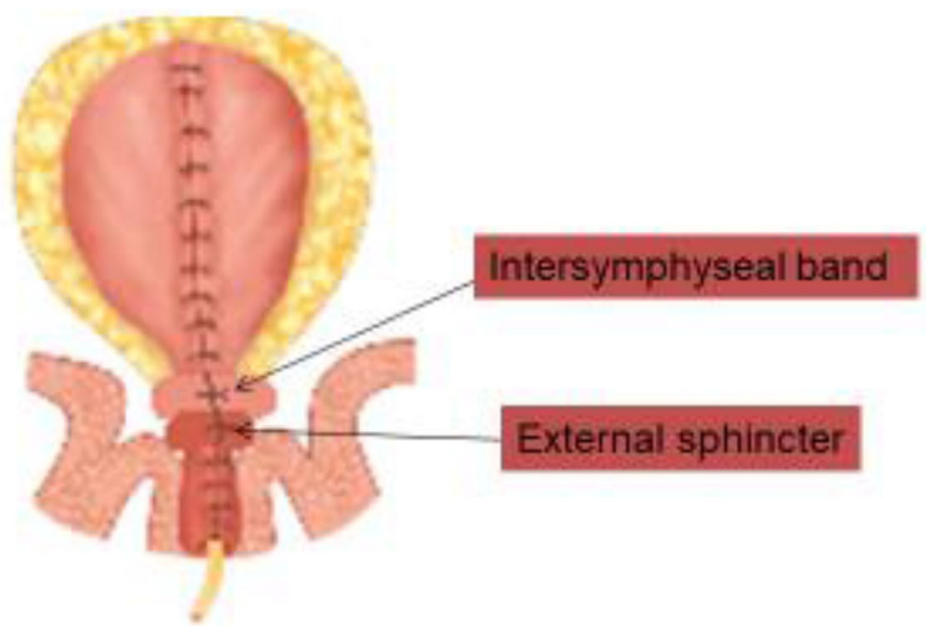

Fig. 2 a Intraoperative anatomy of internal and external sphincter. b Reconstructed sphincters in anatomical repair of bladder exstrophy

\section{Results}

Descriptive statistics and chi-square test.

\section{Results}

All the patients had undergone successful anatomical repair of exstrophy [3].

\section{Histopathology study}

On histopathological analysis of the ISB in the 26 primary cases operated, 25 patients showed smooth muscle (Fig. 3). One patient had a mixture of smooth muscle and fibrosis.

In case of the redo surgeries, 4 out of the 7 patients had fibrosis in the histopathology report. The remaining 3 patients had a mixture of smooth muscle and fibrosis (Table 1).
The pie diagram (Fig. 4) summarizes the histopathology findings in all the patients of the study.

\section{Continence study}

Among the 26 primarily operated patients, 1 patient had to undergo a primary ileocystoplasty due to a minute non-pliable bladder plate not having any potential to grow. This patient has not been included in the continence study.

Twenty-two patients showed a progressive improvement in the dry interval and volitional voiding ability. There was a significant increase in the voided volume as the age and time interval from surgery increased. The US/MCU also documented an increase in bladder capacity (Fig. 5). 


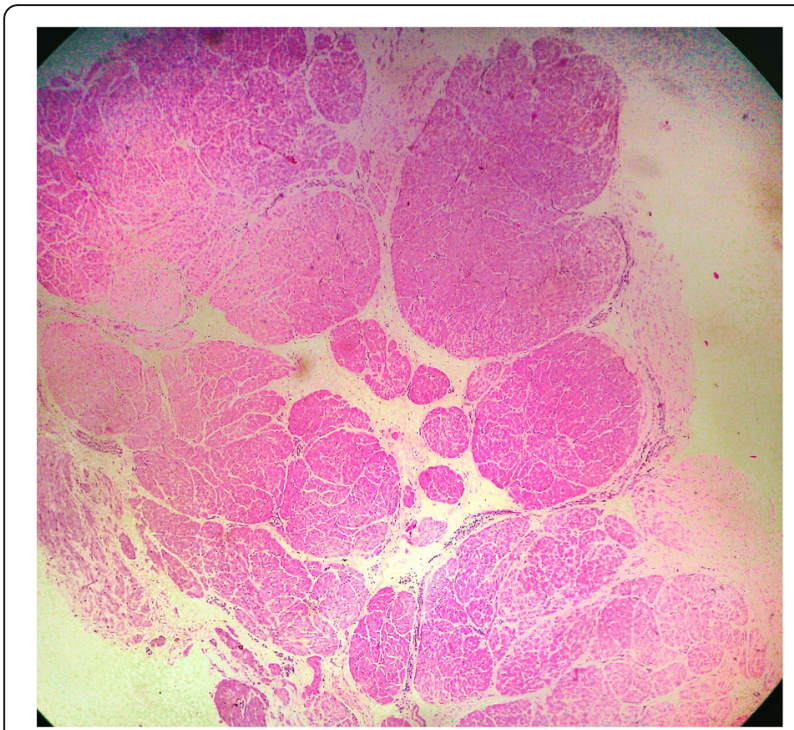

Fig. 3 Histopathological Hand E stain of the ISB showing smooth muscle bundles

The graph (Fig. 6) below shows the definite positive association of the increase in bladder capacity measured on US with the years since surgery was performed.

We would like to mention that the maximum dry interval that we have achieved to date in all our operated patients is $3 \mathrm{~h}$ with volitional voiding. This was mainly achieved 8 years of surgery after which there was no further increase in dry interval.

There was also no deterioration in the status of the upper tracts as measured by regular US.

The remaining 3 patients in this group were incontinent. Of these, one patient has had repeated fungal infections with cystitis which were inadequately treated due to poor compliance. He is now under observation after successful treatment for the same to look for improvement in continence levels.

Among the 7 re-operated patients, 1 patient was lost to follow-up, 3 patients were partly continent with ability to volitionally void but with a shorter dry interval, and 3 patients remained incontinent.

Table 1 Histopathological findings in primary and re-operated patients

\begin{tabular}{|c|c|c|c|c|c|c|}
\hline & \multicolumn{2}{|c|}{ Primary surgery } & \multicolumn{2}{|c|}{ Re-surgery } & \multicolumn{2}{|c|}{ Total } \\
\hline & No. & $\%$ & No. & $\%$ & No. & $\%$ \\
\hline Smooth muscle & 25 & $96.2 \%$ & 0 & $0.0 \%$ & 25 & $75.8 \%$ \\
\hline Mixed tissue & 1 & $3.8 \%$ & 3 & $42.9 \%$ & 4 & $12.1 \%$ \\
\hline Fibrous tissue ${ }^{a}$ & 0 & $0.0 \%$ & 4 & $57.1 \%$ & 4 & $12.1 \%$ \\
\hline Total & 26 & & 7 & & 33 & $100.0 \%$ \\
\hline
\end{tabular}

${ }^{a}$ All patients with fibrous tissue were re-operated patients and probably healed by fibrosis

\section{Correlation of histopathology with continence}

Table 2 followed by the bar chart (Fig. 7) depicts the above correlation using the chi-square test.

\section{Discussion}

The intersymphyseal band (ISB) is an important structure encountered during repair of EEC. This thick band of tissue runs from the exposed bladder plate to the splayed pubic rami and must be divided in order to place the bladder in the pelvis [1].

The origin of this structure considering its normal anatomic counterpart has rarely been studied in literature $[4,5]$. Our attempt to ascertain its origin to the smooth muscle of the bladder neck was to underline its importance in providing continence if properly reconstructed during primary repair of EEC patients.

Normal urinary continence is a complex phenomenon. It depends on a host of factors including bladder compliance and capacity, the integrity of the bladder neck, external urethral sphincter, and an intact nerve supply of the bladder.

Dynamic resistance at the bladder outlet is a wellorchestrated program which makes the bladder neck contract in response to distension of the bladder wall. The smooth muscle of the bladder neck, we believe, is the keystone to remaining dry as the bladder begins to distend with urine up to the point of voluntary voiding or attaining full capacity. It acts even before the first urge to void is felt.

The continence problems faced by operated exstrophy patients occur mainly because of 3 factors:

1. Inadequate bladder capacity

2. Non-compliant bladder

3. Improper bladder neck reconstruction

Having emphasized the importance of the bladder neck smooth muscle, we stress that it is represented by the intersymphyseal band (ISB) in exstrophy patients. This is proved by demonstrating smooth muscle in histopathological sections taken from the ISB during surgery. This band essentially provides the dynamic outlet resistance required in the process of achieving continence. It should hence be preserved and repositioned in its anatomical location, around the bladder neck in the primary surgery itself.

To preserve the nerve supply for adequate physiological function, we insist that during surgery, mobilization of the bladder plate should not extend beyond the uretero-vesical junction.

We think that a well-reconstructed bladder outlet during primary repair of exstrophy patients goes a long way in not only providing dynamic outlet resistance for continence, but also a stimulus for the bladder to grow. This 


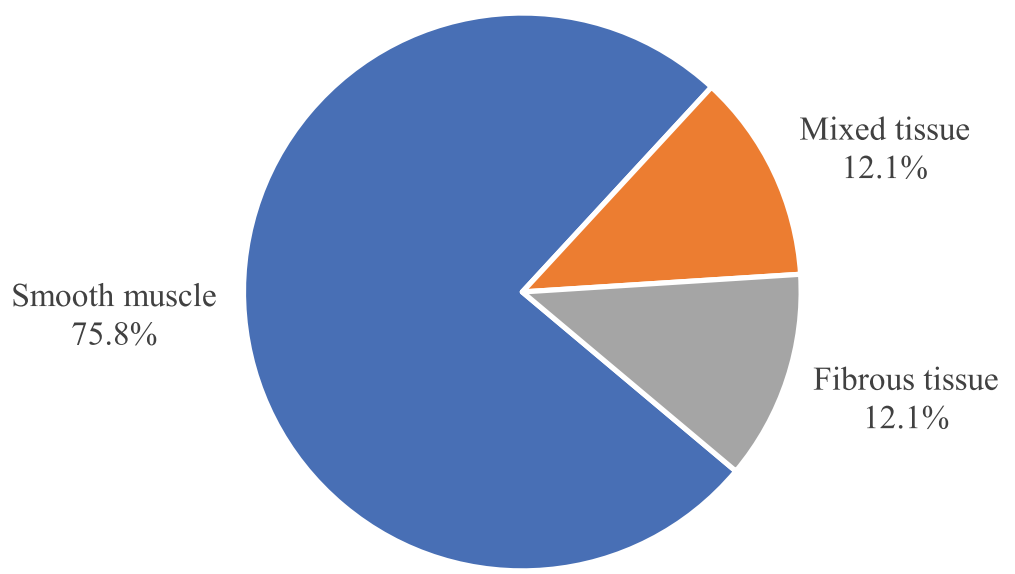

Fig. 4 Pie chart depicting histopathological findings in all patients operated

then helps to increase the dry interval further by an increase in bladder capacity.

Because of our practical constraints, we do surgery at the age of 8 months. If repair is done in the neonatal period, it would further prevent bladder wall inflammation and fibrosis thus increasing the potential in further improvement in bladder capacity.

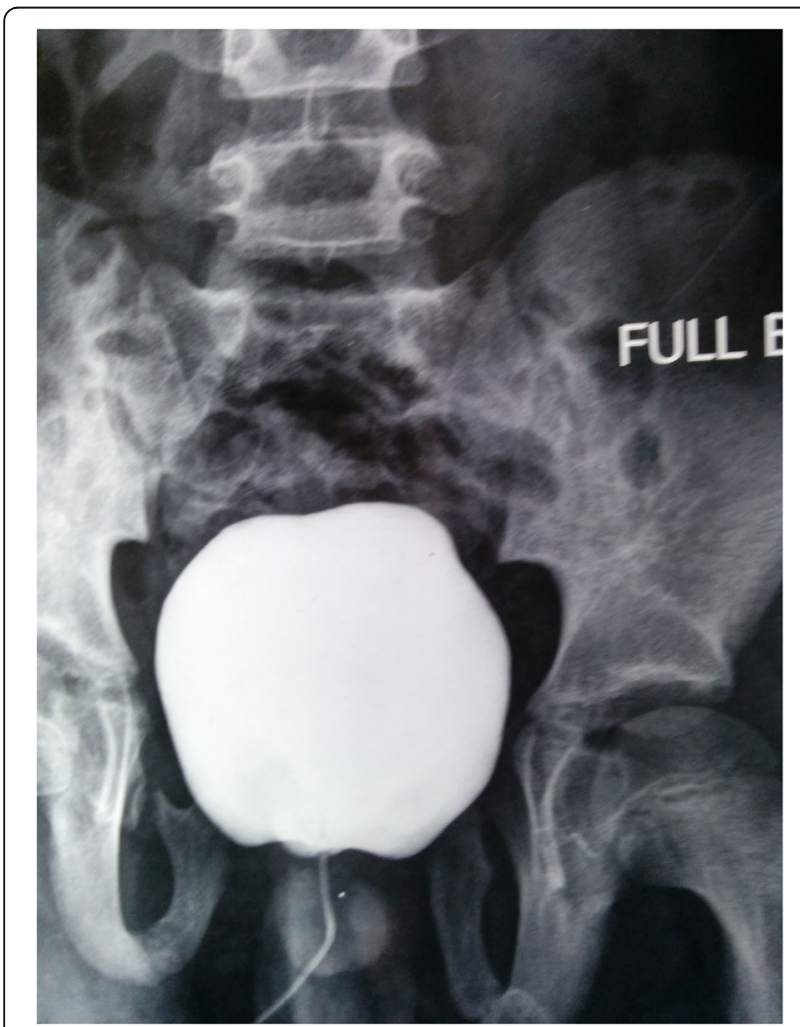

Fig. 5 MCU showing bladder growth post-operatively in an exstrophy patient with a closed bladder neck
A fairly well-grown bladder with a good outlet averts the need of augmentation, which has its own complications. The operated exstrophy patients can be continent with a dry interval of $3 \mathrm{~h}$.

In the cases of redo or staged procedures for repair, the ISB is replaced in part or totally by fibrous tissue. Hence, its ability to provide the dynamic resistance as in muscle is significantly affected. We found that these patients had suboptimal continence levels and many required urinary diversion to solve their problems.

An ideal repair of exstrophy would be one which relocates tissue in their normal anatomical position. The two main procedures widely used today in the repair of exstrophy patients include the complete primary repair of exstrophy (CPRE) [6] and the modern staged repair of exstrophy (MSRE) [7]. Both these methods stress on the importance of dividing the ISB to place the bladder and the posterior urethra deep in the pelvis.

In fact, the author John Brock has advocated the use of a single midline incision through the ISB to place the bladder deep in the pelvis [8].

Thus, the construction of a bladder neck using the ISB is not a part of these procedures.

A few studies have included this step in their procedures.

V. Bhatnagar [9] closed the ISB at the junction of the tubularized paraexstrophy flaps and the bladder. This method adopts a staged approach for closure.

The modified CPRE technique described by Kurbet et al. [10] also includes the wrapping of the ISB around the bladder neck.

The single case reported by Senoh and Yamaguchi [11] has stressed on the fact that closing the ISB around the bladder neck is the single most important factor that ensures urinary continence in exstrophy patients. 


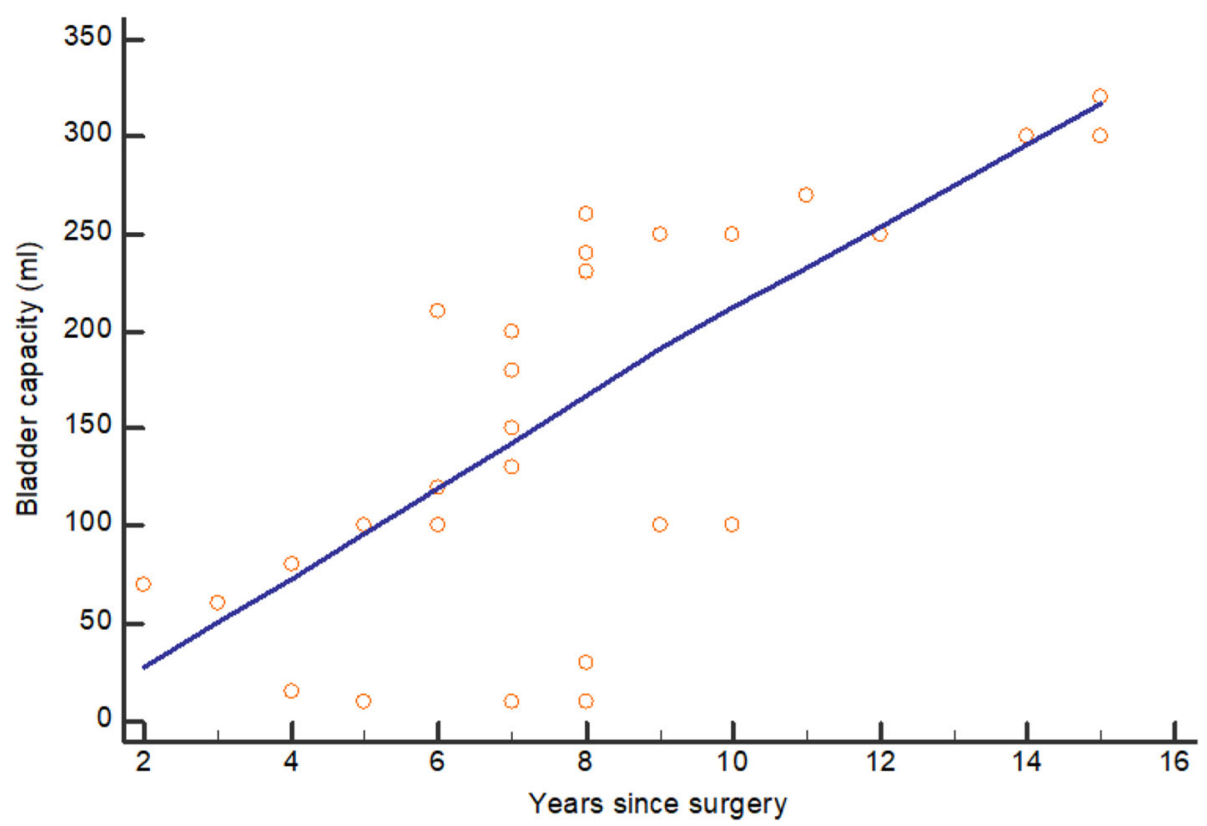

Fig. 6 Graph depicting correlation of bladder capacity with time since surgery

The original research by Wakim et al. [12] on 28-week gestation foetuses studies the musculoskeletal organisation of the urogenital system in classic bladder exstrophy patients. This article also emphasizes the need to preserve and repair these structures during surgery.

The added importance of the external urethral sphincter in continence has been studied by Kureel et al. [13, 14]. Their method includes anatomical repair along with innervation preserving sphincteroplasty of the skeletal muscle of the urogenital diaphragm by dissection in the subperiosteal plane. The continence rates achieved were $71.4 \%$ in single-stage exstrophy repair.

In our previous study of 2004, we too have mentioned about the importance of reconstructing both, the external and internal sphincter [3].

In this study, now we have gone a step further to emphasize this fact by demonstrating that there is smooth muscle in this ISB in all our primarily operated patients.
The smooth muscle of the ISB thus gives dynamic continence in addition to voluntary control of urination provided by the striated muscle of the external urethral sphincter.

\section{Conclusions}

The ISB represents the smooth muscle of the bladder neck in patients of exstrophy.

This band with its intact nerve supply needs to be wrapped around the bladder neck during the primary repair itself to preserve the smooth muscle that it contains. A well-constructed bladder outlet is one of the important factors to give the best chance for development of the bladder as well as acceptable social continence.

Repeated surgeries that involve dissection in this area replace the smooth muscle of the ISB with fibrosis which then has a direct impact on continence.

Table 2 Continence status in patients with different histopathological findings

\begin{tabular}{|c|c|c|c|c|c|c|}
\hline & \multicolumn{2}{|c|}{ Smooth muscle $(n=24)$} & \multicolumn{2}{|c|}{ Mixed tissue $(n=04)$} & \multicolumn{2}{|c|}{ Fibrous tissue $(n=03)$} \\
\hline & No. & $\%$ & No. & $\%$ & No. & $\%$ \\
\hline Continent & 22 & $91.7 \%$ & 0 & $0.0 \%$ & 0 & $0.0 \%$ \\
\hline Partly continent & 0 & $0.0 \%$ & 3 & $75.0 \%$ & 0 & $0.0 \%$ \\
\hline Incontinent & 2 & $8.3 \%$ & 1 & $25.0 \%$ & 3 & $100.0 \%$ \\
\hline
\end{tabular}

$x^{2}=38.319, p<0.0001$ 


\section{- Continent $\quad$ Partly Continent $\quad$ Incontinent}

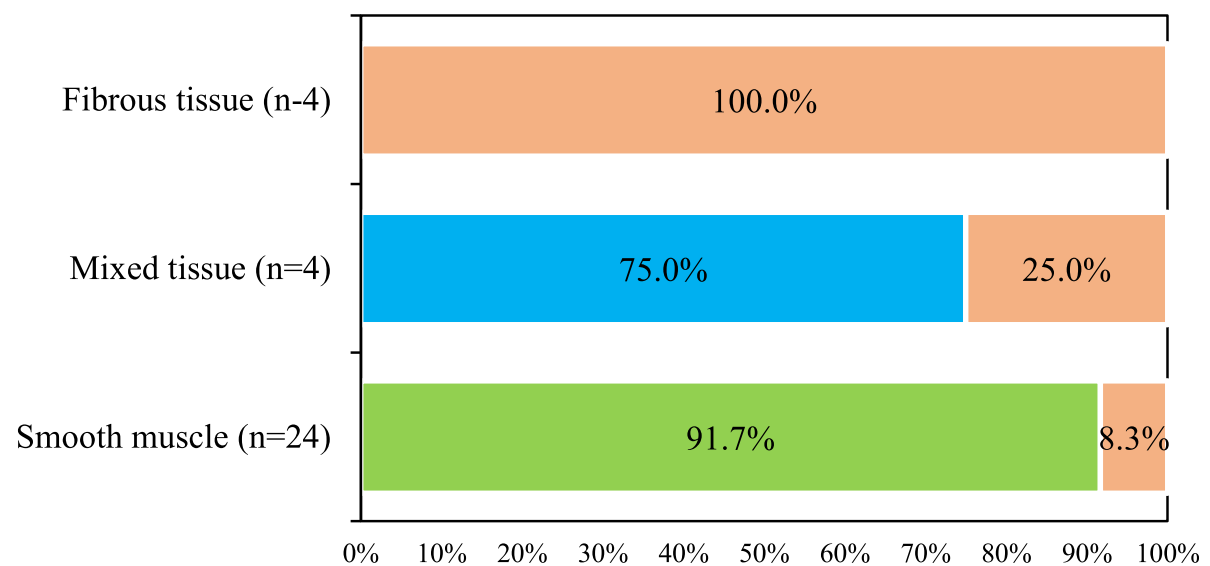

Fig. 7 Bar chart depicting continence status in patients with different histopathological findings

Hence, successful single-stage repair should be the aim of reconstruction.

\section{Limitations of study}

It would be expected to have a control group but due to the severity and frequency of this disease, it is not easy to obtain comparable two groups at a same time.

\section{Abbreviations}

EEC: Exstrophy epispadias complex; ISB: Intersymphyseal band;

US: Ultrasound; MCU: Micturating cystourethrogram; CPRE: Complete primary repair of exstrophy; MSRE: Modern staged repair of exstrophy

\section{Acknowledgements}

The authors would like to acknowledge Dr. Deepak Langade, Professor and HOD, Department of Pharmacology for his guidance in the statistical analysis of our data.

\section{Authors' contributions}

BKK made substantial contributions to the concept, design and interpretation of data. NS made contributions to the design, acquisition, analysis and interpretation of data. SSB, HNL, PM, and DSG drafted the work and substantially revised it. All authors have approved the submitted version of the manuscript. All authors have agreed both to be personally accountable for their own contributions and to ensure that questions related to the accuracy or integrity of any part of the work, even ones in which he/ she was not personally involved, are appropriately investigated, resolved, and the resolution documented in the literature.

\section{Funding}

This research did not receive any specific grant from funding agencies in the public, commercial, or not-for-profit sectors.

\section{Availability of data and materials}

The datasets used and/or analyzed during the current study are available from the corresponding author on reasonable request.

\section{Declarations}

\section{Ethics approval and consent to participate}

We hereby declare that our study was approved by the Institutional Ethics Committee, D Y Patil Deemed To Be University School of Medicine, Navi Mumbai (ECR/195/Inst/MH/RR19). All procedures performed in the study were in accordance with the ethical standards of the institutional and/or national research committee and with the 1964 Helsinki declaration and its later amendments or comparable ethical standards.

\section{Consent for publication}

Informed consent was obtained from all individual participants/their parents in the study.

\section{Competing interests}

The authors declare that they have no competing interests.

Received: 30 April 2021 Accepted: 29 August 2021

Published online: 06 December 2021

References

1. Gearhart JP, Mathews R. Exstrophy- Epispadias Complex. In: Wein AJ, Kavoussi LR, Novick AC, Partin AW, Peters CA, editors. Campbell-Walsh Urology. 9th ed. Philadelphia: Saunders ElsevierP; 2007. p. 3503.

2. Kurpad A. Micturition. In: Hall JE, Hall ME, editors. Guyton and Hall Textbook of Medical Physiology. 3rd South Asia ed: RELX India Private Limited; 2020 p. 565.

3. Bharati K, Ashish J, Kumar T, Paras K. Anatomical repair of exstrophy bladder Pediatr Surg Int. 2004;20(6):455-9. https://doi.org/10.1007/s00383-004-1175-x Epub 2004 May 18. PMID: 15148616.

4. Canning DA, Parrillo L, Gupta K, Snyder HM. Bladder Exstrophy. In: Ziegler MM, Azizkhan RG, Allmen D, Weber TR, editors. Operative Pediatric Surgery. 2nd ed. New York: Mc Graw Hill Education; 2014.

5. Prabudh G, Kureel SN. Intersymphyseal band in exstrophy bladder: a histological study to ascertain its structure of origin. J Prog Paediatr Urol. 2013;16(2):70 http://www.paediatric-urologyonline.org/jppu/pdf/issue2/a bstracts.pdf

6. Grady RW, Mitchell ME. Complete primary repair of exstrophy. J Urol. 1999; 162(4):1415-20. https://doi.org/10.1016/S0022-5347(05)68327-9.

7. Lepor $\mathrm{H}$, Jeffs RD. Primary bladder closure and bladder neck reconstruction in classical bladder exstrophy. J Urol. 1983;130(6):1142-5. https://doi.org/10.1 016/S0022-5347(17)51727-9.

8. Brock JW III, DeMarco RT, O'Neill JA Jr. Bladder and cloacal exstrophy. In: Grosfeld JL, O’Neill Jr JA, Coran AG, Fonkalsrud E, editors. Pediatric Surgery. 6th ed. Philadelphia: Mosby Elsevier; 2006. p. 1856.

9. Bhatnagar $\mathrm{V}$. Bladder exstrophy: An overview of the surgical management. J Indian Assoc Pediatr Surg. 2011;16(3):81-7. https://doi.org/10.4103/0971-92 61.83483

10. Kurbet SB, Prashanth GP, Patil MV, Mane S. A retrospective analysis of early experience with modified complete primary repair of exstrophy bladder (CPRE) in neonates and children. Indian J Plast Surg. 2013:46(3):549-54. https://doi.org/10.4103/0970-0358.122015. 
11. Senoh $\mathrm{K}$, Yamaguchi T. Long term follow up of a bladder exstrophy case after successful repair. Nihon Hinyokika Gakkai Zasshi. 1999;90(5):572-8. https://doi.org/10.5980/jpnjurol1989.90.572.

12. Wakim A, Barbet JP. Connections of the bladder plate and bladder neck with the bony pelvis in a fetus with classic bladder exstrophy. Urology. 2002;60(1):142-6. https://doi.org/10.1016/S0090-4295(02)01715-6.

13. Kureel SN, Gupta A, Kumar S, Dalela D. A novel midline scroto-perineal approach facilitating innervation preserving sphincteroplasty and radical corporal detachment for reconstruction of exstrophy-epispadias. Urology. 2011;78(3):668-74. https://doi.org/10.1016/j.urology.2010.12.086.

14. Gupta A, Kureel SN, Wakhlu A, Rawat J. Bladder exstrophy: comparison of anatomical bladder neck repair with innervation preserving sphincteroplasty versus Young-Dees-Leadbetter bladder neck reconstruction. J Indian Assoc Pediatr Surg. 2013;18(2):69-73. https://doi.org/10.4103/0971-9261.109356 PMID: 23798810; PMCID: PMC3687150.

\section{Publisher's Note}

Springer Nature remains neutral with regard to jurisdictional claims in published maps and institutional affiliations.

\section{Submit your manuscript to a SpringerOpen ${ }^{\circ}$ journal and benefit from:}

- Convenient online submission

- Rigorous peer review

- Open access: articles freely available online

High visibility within the field

- Retaining the copyright to your article

Submit your next manuscript at $\boldsymbol{\nabla}$ springeropen.com 